\title{
Cumulative mortality in children aged 1 to 6 years born in Western Australia from 1980-89
}

\author{
Louisa M Alessandri, Helen M Chambers, Carol Garfield, Sharon Vukovich, \\ Anne W Read
}

\begin{abstract}
Purpose-To investigate cumulative mortality for children aged 1-6 years born in Western Australia from 1980 to 1989. Study design-Births and deaths were ascertained from a linked total population database supplemented by information from postmortem records. Deaths were classified according to the underlying cause, and mortality rates, including factor specific rates, were calculated. Trends were investigated and comparisons were made using relative risks with $95 \%$ confidence intervals.
\end{abstract}

Results-Cumulative mortality was 2.21 1000 infant survivors, with a significant decrease during the years studied. Mortality was almost four times higher for Indigenous children, with no decrease. Accidents comprised $45.6 \%$ of all deaths, birth defects $17.3 \%$, cancer and leukaemias $12.5 \%$, and infections $11.0 \%$. Low birth weight, preterm birth, and young maternal age significantly increased the risk of death in both Indigenous and nonIndigenous children; single marital status was also a significant risk factor for non-Indigenous children.

Conclusion-High quality data and appropriate classification systems are essential to enable effective monitoring of childhood deaths and the planning of preventive programmes. Further decreases in mortality rates might be dependent on ensuring that resources are directed towards improving social and economic conditions for Indigenous and other disadvantaged families.

(Arch Dis Child 1999;80:15-20)

Division of
Epidemiology, TVW

Telethon Institute for

Child Health

Research, PO Box 855,

Perth, Western

Australia 6872,

Australia

L M Alessandri

C Garfield

$S$ Vukovich

A W Read

King Edward

Memorial and

Princess Margaret

Hospitals, Perth,

Western Australia

6008, Australia

$\mathrm{H}$ M Chambers

Correspondence to: Dr Read.

Accepted 30 June 1998

Keywords: mortality; Western Australia; cause of death; epidemiology

Recent literature on childhood mortality in industrialised countries focuses on accidents and/or injuries as the major causes of childhood deaths. ${ }^{1-6}$ There is little that deals with the overall patterns of childhood mortality and, in particular, we have been unable to find any investigations on the specific causes of childhood mortality for birth cohorts for a total population.

Previous work in Western Australia has highlighted the importance of considering the Indigenous (see editors' note) status of the child when analysing mortality data in infancy because Indigenous infants have been shown to have much higher postneonatal and infant mortality than non-Indigenous infants. ${ }^{7-9}$ The leading causes of death in infancy also differ in the two populations, with sudden infant death syndrome (SIDS) being the major cause of death for Indigenous infants and birth defects for non-Indigenous infants. ${ }^{9}$

The aim of our retrospective, longitudinal study was to investigate childhood mortality for all children aged 1-6 years inclusive born from 1980 to 1989 and dying from 1981 to 1996 inclusive in Western Australia. The available data for these birth cohorts allowed us to compare trends and causes of childhood mortality for the Indigenous and non-Indigenous populations, and to investigate the data according to selected maternal and infant variables, to obtain information that would be useful in assisting with the planning of preventive strategies for childhood deaths.

\section{Methods}

All children born in Western Australia from 1980 to 1989 inclusive were ascertained from the Western Australia maternal and child health research database (MCHRDB). ${ }^{10}$ This database includes death information linked to birth data for all births in Western Australia from 1980 onwards. Infant survivors from the 1980 to 1989 birth cohorts were followed to their 7th birthdays to ascertain which children had died between the ages of 1 and 6 years inclusive. Cause of death data for the MCHRDB are obtained from the Registrar General of Western Australia via the Australian Bureau of Statistics (ABS). The Registrar General's Office collects descriptive data pertaining to the cause of death from death certificates; these data are then forwarded to the ABS, where they are coded according to the International classification of diseases 9 th revision (ICD-9). ${ }^{11}$
Table 1 Childhood deaths for children aged 1-6 years born in Western Australia 1980-89

\begin{tabular}{lrlllll}
\hline \multirow{7}{*}{ Year of birth } & \multicolumn{2}{c}{ Rate/1000 infant survivors $(n)$} \\
\cline { 2 - 6 } & \multicolumn{2}{c}{ Indigenous } & \multicolumn{3}{l}{ Non-Indigenous } & Total \\
\hline 1980 & 7.0 & $(7)$ & 2.7 & $(52)$ & 3.0 & $(61)$ \\
1981 & 11.2 & $(12)$ & 2.5 & $(51)$ & 2.9 & $(64)$ \\
1982 & 3.7 & $(4)$ & 2.0 & $(41)$ & 2.1 & $(46)$ \\
1983 & 10.8 & $(12)$ & 1.8 & $(39)$ & 2.3 & $(51)$ \\
1984 & 9.6 & $(11)$ & 2.1 & $(44)$ & 2.4 & $(55)$ \\
1985 & 6.7 & $(8)$ & 1.6 & $(35)$ & 1.9 & $(44)$ \\
1986 & 6.7 & $(8)$ & 1.3 & $(28)$ & 1.5 & $(36)$ \\
1987 & 6.1 & $(8)$ & 1.8 & $(41)$ & 2.1 & $(49)$ \\
1988 & 5.8 & $(8)$ & 1.5 & $(36)$ & 1.8 & $(45)$ \\
1989 & 7.1 & $(10)$ & 1.7 & $(41)$ & 2.0 & $(51)$ \\
$1980-89$ & 7.4 & $(88)$ & 1.9 & $(408)$ & 2.2 & $(502)^{\star}$ \\
$\chi^{2}$ for trend & 0.80 & 10.40 & 11.20 & \\
p value & 0.370 & 0.001 & 0.001
\end{tabular}

^There were six childhood deaths where the race was unknown. 
Table 2 Cause of childhood deaths by Indigenous status for children aged 1-6 years born in Western Australia from 1980-89

\begin{tabular}{lcll}
\hline & \multicolumn{2}{l}{ Rate/10000 infant survivors (n) } & \\
\cline { 2 - 3 } Cause of death & $\begin{array}{l}\text { Indigenous } \\
(n=88)\end{array}$ & $\begin{array}{l}\text { Non-Indigenous } \\
(n=407)\end{array}$ & $\begin{array}{l}\text { Relative risk } \\
(95 \% \text { CI) }\end{array}$ \\
\hline Birth defects & $9.3(11)$ & $3.4(74)$ & $2.7(1.5$ to 5.1$)$ \\
Infections & $16.0(19)$ & $1.7(36)$ & $9.7(5.6$ to 16.9$)$ \\
Sudden infant death syndrome & $1.7(2)$ & $0.7(15)$ & $2.5(0.6$ to 0.7$)$ \\
Accidents & $37.9(45)$ & $8.3(181)$ & $4.6(3.3$ to 6.3$)$ \\
Cancer and leukaemias & $2.5(3)$ & $2.8(60)$ & $0.9(0.3$ to 2.9$)$ \\
Neurological conditions & $5.1(6)$ & $0.7(15)$ & $7.3(2.9$ to 18.9$)$ \\
Other & $1.7(2)$ & $0.8(18)$ & $2.0(0.5$ to 8.8$)$ \\
Unascertainable & - & $0.4(8)$ & - \\
\hline
\end{tabular}

There was one non-Indigenous childhood death caused by perinatal conditions.

${ }^{\star}$ Excludes six deaths where race was unknown.

To validate the cause of death data from the MCHRDB, postmortem records were obtained for as many childhood deaths as possible. Postmortem data were collected from three major centres, the forensic pathology section of the Western Australia State Health Laboratory Services in Perth, Princess Margaret Hospital for Children (PMH) (the only tertiary paediatric hospital in Western Australia), and the Perth Coroner's Office. All sudden and unexpected childhood deaths in Western Australia are reported to the State Coroner and must undergo a postmortem examination. Most of these examinations are conducted centrally at the forensic pathology section. Although some of the accidental deaths that occur in the country areas have postmortem examinations performed locally, postmortem records from 1986 onwards have been held at the Perth Coroner's Office. For country deaths from 1980 to 1985 , the records are held at the Coroner's Court in the appropriate country region. There are eight such country regions and all were contacted by mail to obtain postmortem information.

Since 1990, all postmortem examinations carried out under the State Coroner on sudden and unexpected deaths up to the age of 2 years, other than those related to accidents, have been attended by and the material reviewed by specialised paediatric pathologists based at PMH. Postmortem examinations on children who were admitted and died at PMH were conducted by the same pathologists at the hospital. The birth defects registry of Western Australia, ${ }^{12}$ which is linked to the MCHRDB, was also used as a data source to ascertain postmortem information for those deaths where records could not be found at the above centres. After all information was gathered, these data were compared with the cause of

Table 3 Deaths by age at death and major cause for non-Indigenous children aged 1-6 years born in Western Australia 1980-89

\begin{tabular}{llllll}
\hline \multicolumn{5}{c}{ Rate/10000 infant survivors $(n)$} \\
\cline { 2 - 6 } Age & Accidents & $\begin{array}{l}\text { Birth } \\
\text { defects }\end{array}$ & Infections & $\begin{array}{l}\text { Cancer and } \\
\text { leukaemias }\end{array}$ & All causes \\
\hline 1 & $2.8(61)$ & $1.6(34)$ & $0.4(9)$ & $0.6(13)$ & $6.6(143)$ \\
2 & $1.8(40)$ & $0.9(19)$ & $0.5(11)$ & $0.3(6)$ & $3.9(85)$ \\
3 & $1.6(34)$ & $0.5(10)$ & $0.3(7)$ & $0.7(15)$ & $3.3(72)$ \\
4 & $0.9(19)$ & $0.2(4)$ & $0.1(2)$ & $0.6(12)$ & $2.1(45)$ \\
5 & $0.7(16)$ & $0.1(2)$ & $0.1(3)$ & $0.4(9)$ & $1.6(35)$ \\
6 & $0.6(12)$ & $0.2(5)$ & $0.2(4)$ & $0.2(5)$ & $1.3(28)$ \\
\hline
\end{tabular}

death information recorded on the MCHRDB to determine if there were any discrepancies.

A simple and broad classification system for cause of childhood death was designed with the aim of identifying major changes in causation over time, and such that it was useful in identifying preventable causes of death. Under this system, all deaths were classified into major groupings according to the condition that was thought to be the underlying cause. The major groups were conditions originating in the perinatal period, birth defects, infections, SIDS (as diagnosed by necropsy), accidents, cancer and leukaemia, neurological conditions, other, and unknown or unascertainable. The category "other" included uncommon but specific causes of death (such as cardiomyopathy and mechanical bowel obstruction). Accidents were classified further into road traffic accidents, drowning, poisoning, deaths attributable to fire, other accidents, and homicide. The "other accident" group included farm accidents, accidental mechanical suffocation, choking, and blows from falling objects. All the childhood deaths were classified independently by three of the authors (LA, AR, and HC). Any disagreement was resolved by discussion. If the cause of death data from the MCHRDB differed from that derived from the postmortem data, the latter took precedence.

Information on maternal race, age, parity, and marital status (as recorded at the birth of the child, de facto partnerships being included in the married category), and on sex, birth weight, and gestational age of the child at birth were obtained from the MCHRDB. Children with Aboriginal or Torres Strait Islander mothers were classified as Indigenous children. Other data such as age at death were collected from death certificates. SAS computer software ${ }^{13}$ was used for data entry and manipulation and for obtaining frequencies. Overall rates of childhood death for birth cohorts 1980 to 1989 were calculated for each 1000 infant survivors by Indigenous status and for each 10000 infant survivors by cause of death. Factor specific childhood mortality rates were calculated for all children for total mortality and, for non-Indigenous children for major cause of death categories. This latter analysis was not performed for Indigenous children because of small numbers in some categories. Unknown values were few and were excluded from all calculations. Chi squared tests for trend were calculated to investigate trends in mortality over time, and relative risks with Taylor series $95 \%$ confidence intervals (CI) were calculated to compare rates using the EpiInfo software package. ${ }^{14}$ The denominators for all rates were obtained from the MCHRDB.

\section{Results}

There were 502 deaths of children aged 1-6 years ascertained for our study. Death information from the ABS could not be linked to birth information on the MCHRDB for four of these deaths; two of these four children had been adopted. Postmortem records were found for $67.3 \%(n=338)$ of the total deaths. Most of these records $(66.9 \% ; n=226)$ were located 
Table 4 Deaths by Indigenous status and selected maternal and infant variables for children aged 1-6 years born in Western Australia 1980-89

\begin{tabular}{|c|c|c|c|c|}
\hline & \multicolumn{2}{|l|}{ Indigenous } & \multicolumn{2}{|l|}{ Non-Indigenous } \\
\hline & $\begin{array}{l}\text { Rate/1000 infant } \\
\text { survivors }(n)\end{array}$ & $\begin{array}{l}\text { Relative risk } \\
(95 \% \mathrm{CI})\end{array}$ & $\begin{array}{l}\text { Rate/1000 infant } \\
\text { survivors }(n)\end{array}$ & $\begin{array}{l}\text { Relative risk } \\
(95 \% \mathrm{CI})\end{array}$ \\
\hline \multicolumn{5}{|l|}{ Sex } \\
\hline Female & $7.3(43)$ & - & $1.7(178)$ & - \\
\hline Male & $7.5(45)$ & $1.0(0.7$ to 1.5$)$ & $2.1(230)$ & $1.2(1.0$ to 1.5$)$ \\
\hline \multicolumn{5}{|l|}{ Birth weight } \\
\hline$\geqslant 2500 \mathrm{~g}$ & $6.8(72)$ & - & $1.8(370)$ & - \\
\hline$<2500 \mathrm{~g}$ & $12.4(16)$ & $1.8(1.1$ to 3.1$)$ & $3.5(38)$ & $1.9(1.4$ to 2.7$)$ \\
\hline \multicolumn{5}{|l|}{ Gestational age } \\
\hline$\geqslant 37$ weeks & $6.3(62)$ & - & $1.8(364)$ & - \\
\hline$<37$ weeks & $12.9(21)$ & 2.1 (1.3 to 3.4$)$ & $3.0(44)$ & 1.7 (1.2 to 2.3$)$ \\
\hline \multicolumn{5}{|l|}{ Maternal age ${ }^{\star}$} \\
\hline$\geqslant 20$ years & $6.1(48)$ & - & $1.8(375)$ & - \\
\hline$<20$ years & $10.1(40)$ & $1.7(1.1$ to 2.5$)$ & $2.8(33)$ & $1.6(1.1$ to 2.2$)$ \\
\hline \multicolumn{5}{|l|}{ Parity ${ }^{\star}$} \\
\hline 0 & $8.3(30)$ & - & $1.7(143)$ & - \\
\hline$\geqslant 1$ & $7.1(58)$ & 0.9 (0.6 to 1.3$)$ & $2.0(259)$ & $1.2(1.0$ to 1.5$)$ \\
\hline \multicolumn{5}{|l|}{ Marital status* } \\
\hline Married/de facto & $7.8(52)$ & - & $1.8(347)$ & - \\
\hline Single/other† & $6.9(36)$ & $0.9(0.6$ to 1.3$)$ & $3.2(61)$ & $1.8(1.4$ to 2.4$)$ \\
\hline
\end{tabular}

$\star$ At birth of child

†Separated, divorced, or widowed.

at the forensic pathology section of the State Health Laboratory Services, with $17.2 \%$ $(n=58)$ being ascertained from PMH, 13.6\% $(\mathrm{n}=46)$ from the Perth Coroner's Office, $1.8 \%(n=6)$ from Country Coroners' Courts, and $0.6 \%(n=2)$ from the Birth Defects Registry. Postmortem records could not be found for five deaths that were identified as Coroner's cases on the death certificate. All of the eight Country Coroners' Courts replied to our request for data but only three could provide information, the other regions being unable to locate the records required. The proportion of Indigenous childhood deaths $(71.6 \%)$ for which postmortem information was ascertained was slightly higher than that for non-Indigenous children $(66.4 \%)$. There was discrepancy between postmortem information and the MCHRDB in only nine $(1.8 \%)$ of the total childhood deaths. Of the 17 deaths $(3.4 \%)$ where there was initial disagreement between the authors as to the classified cause of death, all were subsequently reclassified with complete agreement.
The cumulative incidence of death for children aged from 1 to 6 years born from 1980 to 1989 in Western Australia was 2.2/1000 infant survivors. The rate decreased significantly over time for the total population and for non-Indigenous children but not for Indigenous children (table 1). The relative risk for Indigenous compared with non-Indigenous children was 4.0 (95\% CI, 3.1 to 5.0 ).

In both Indigenous and non-Indigenous populations, the cumulative mortality for the ages studied was highest for accidents. The leading causes of death for Indigenous children were accidents, followed by infections, and birth defects, whereas for non-Indigenous children they were accidents, followed by birth defects, and cancer and leukaemias. The Indigenous population had higher rates of childhood deaths for all causes except cancer and leukaemias, where the rates were very similar. The greatest disparity between the Indigenous and non-Indigenous populations was for childhood deaths caused by infections, the relative risk being 9.7 (table 2).

Within the accident category, differences were seen between Indigenous and nonIndigenous children, with the former being more likely to die from road traffic accidents (rate, 12.6/10 000 infant survivors) and the latter from drowning (rate, 3.2/10 000 infant survivors). The mortality rate for nonIndigenous children for road traffic accidents was $2.3 / 10000$ and the rate for Indigenous children for drowning was $8.4 / 10000$. Death as a result of fire was grossly excessive in the Indigenous population with a rate of 7.6/ 10000 infant survivors compared with $0.1 /$ 10000 for non-Indigenous children (data not shown).

As age increased, the incidence of death decreased but accidents were the major cause of death in each age group. Drownings accounted for the major proportion of accidental deaths in the younger age groups, whereas road traffic accidents were responsible for most of the accidental deaths in the older age groups (data not shown). Of the other causes, birth

Table 5 Deaths by selected maternal and infant variables and major cause for non-Indigenous children aged 1-6 years born in Western Australia 1980-89

\begin{tabular}{|c|c|c|c|c|c|c|c|c|}
\hline & \multicolumn{2}{|c|}{ Birth defects } & \multicolumn{2}{|l|}{ Infections } & \multicolumn{2}{|l|}{ Accidents } & \multicolumn{2}{|c|}{ Cancer and leukaemias } \\
\hline & Rate $^{\star}(n)$ & $R R(95 \% C I)$ & Rate $^{\star}(n)$ & $R R(95 \% C I)$ & Rate $^{\star}(n)$ & $R R+(95 \% C I)$ & Rate $^{\star}(n)$ & $R R(95 \% C I)$ \\
\hline \multicolumn{9}{|l|}{ Sex } \\
\hline Girl & $3.3(35)$ & - & $1.4(15)$ & - & $6.9(73)$ & - & $2.6(28)$ & - \\
\hline Boy & $3.5(39)$ & $1.1(0.7$ to 1.7$)$ & $1.9(21)$ & $1.3(0.7$ to 2.6$)$ & $9.7(108)$ & $1.5(1.1$ to 2.0$)$ & $2.9(32)$ & 1.1 (0.7 to 1.8$)$ \\
\hline \multicolumn{9}{|l|}{ Birth weight } \\
\hline$\geqslant 2500 \mathrm{~g}$ & $3.0(62)$ & - & $1.5(31)$ & - & $8.2(169)$ & - & $2.8(58)$ & - \\
\hline$<2500 \mathrm{~g}$ & $10.9(12)$ & $3.6(2.0$ to 6.8$)$ & $4.5(5)$ & $3.0(1.2$ to 7.8$)$ & $10.9(12)$ & $1.3(0.7$ to 2.4$)$ & $1.8(2)$ & 0.7 (0.2 to 2.7$)$ \\
\hline \multicolumn{9}{|l|}{ Gestational age } \\
\hline$\geqslant 37$ weeks & $3.1(63)$ & - & $1.5(31)$ & - & $8.3(168)$ & - & $2.7(55)$ & - \\
\hline$<37$ weeks & $7.5(11)$ & $2.4(1.3$ to 4.6$)$ & $3.4(5)$ & $2.2(0.9$ to 5.7$)$ & $8.9(13)$ & $1.1(0.6$ to 1.9$)$ & $3.4(5)$ & $1.3(0.5$ to 3.1$)$ \\
\hline \multicolumn{9}{|l|}{ Maternal age } \\
\hline$\geqslant 20$ years & $3.4(69)$ & - & $1.6(33)$ & - & $7.9(162)$ & - & $2.7(56)$ & - \\
\hline$<20$ years & $4.3(5)$ & $1.3(0.5$ to 3.2$)$ & $2.6(3)$ & $1.6(0.5$ to 5.2$)$ & $16.3(19)$ & $2.1(1.3$ to 3.3$)$ & $3.4(4)$ & $1.3(0.5$ to 3.5$)$ \\
\hline \multicolumn{9}{|l|}{ Parity† } \\
\hline 0 & $3.5(30)$ & - & $1.9(16)$ & - & $6.5(55)$ & - & $3.4(29)$ & - \\
\hline$\geqslant 1$ & $3.4(44)$ & $1.0(0.6$ to 1.5$)$ & $1.5(20)$ & $0.8(0.4$ to 1.6$)$ & $9.6(126)$ & $1.5(1.1$ to 2.1$)$ & $2.4(31)$ & $0.7(0.4$ to 1.2$)$ \\
\hline \multicolumn{9}{|l|}{ Marital status $\dagger$} \\
\hline Married/de facto & $3.4(68)$ & - & $1.3(25)$ & - & $7.7(152)$ & - & $2.7(54)$ & - \\
\hline Single/other $\ddagger$ & $3.2(6)$ & $0.9(0.4$ to 2.1$)$ & $5.8(11)$ & $4.6(2.3$ to 9.3$)$ & $15.2(29)$ & $2.0(1.3$ to 3.0$)$ & $3.2(6)$ & $1.2(0.5$ to 2.7$)$ \\
\hline
\end{tabular}

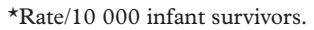

†At birth of child.

$\ddagger$ Separated, divorced, or widowed. 
defects and infections were more important in the younger age groups, whereas cancer and leukaemias were more important causes of death for older children (table 3 ).

In the Indigenous population, low birth weight, preterm birth, and young maternal age were significant risk factors for all causes of childhood mortality. In addition to these factors, for non-Indigenous children, single marital status was significant (table 4). When analysing the variables of interest by the major cause of death groups for non-Indigenous children only (table 5), it was found that the variables analysed were not necessarily risk factors for each cause of death. Boys were at significantly increased risk of dying from accidents but not from the other major causes of childhood death. Low birth weight was an important risk factor for childhood deaths attributable to birth defects and infections. Children of teenage mothers were at significantly increased risk of dying from accidents, whereas those of single mothers had a significant increase in risk from both infections and accidents. None of the factors investigated were associated with an increased risk of childhood death from cancer and leukaemias.

\section{Discussion}

In Western Australia, the 1-6 years mortality rate for non-Indigenous children born during the 1980 s decreased significantly over time. No such decreases were seen for Indigenous children, who remained at much higher risk. Children of young mothers and unsupported mothers were also at increased risk of childhood death, as were children who were preterm or low birth weight. The major cause of death for all children was accidents.

Longitudinal research of this type is rare in the literature and we have been unable to find any similar studies using the cumulative incidence of mortality with which to compare our results. Data to document and analyse total mortality for individual children during the entire course of childhood are rarely available. Thus, most researchers use the population prevalence when investigating childhood mortality. Cumulative incidence allows more precise estimation of rates and more accurate investigation of time trends and risk factors.

Substantial declines in mortality for children (aged 1-4 and 1-14 years) have been reported recently from both industrialised and other countries, ${ }^{15-17}$ and the excess in mortality for Indigenous children has been described in other Australian studies. ${ }^{18-20}$ Our study highlights the ongoing disadvantage for these children. Indigenous populations such as Indians in the USA and Canada also have higher rates of childhood mortality than the corresponding white population or the nation as a whole. ${ }^{171-23}$ Indigenous families in Australia are known to live in poorer socioeconomic and environmental conditions than non-Indigenous families, ${ }^{20}{ }^{24}$ and the relation between low socioeconomic class and high childhood mortality has been well documented. ${ }^{17} 25-27$

\section{Key messages}

- In Western Australia, all cause mortality in early childhood has significantly decreased for later born cohorts

- There was no decrease for Indigenous children

- Much of the disparity between the two populations was attributable to potentially preventable causes, such as accidents and infections

- There is scope to reduce this excess mortality but any intervention must be implemented in close collaboration with the Indigenous community

- Accidents and infections are also excessive for the infants of young and unsupported mothers in the overall population

The overall ranking of causes of death is similar to that seen in Sweden and the USA, ${ }^{16}{ }^{17}$ with the potentially preventable cause of accidents being of major importance..$^{3-5} 1728$ The most striking difference between Indigenous and non-Indigenous children was in the rate of deaths attributable to infection, another potentially preventable cause, and one for which Indigenous children are about 10 times more likely to be admitted to hospital. ${ }^{29}$

The association of factors such as preterm birth, low birth weight, young mothers, and single mothers with high rates of perinatal and infant mortality is well established,,$^{30-32}$ and it appears from this study and others that the disadvantage conferred by their impact persists throughout childhood. ${ }^{33}{ }^{34}$ In the UK, it has been suggested that the increased injury rates for the children of single mothers can be explained by the poverty, poor housing conditions, and social isolation of these mothers. ${ }^{35}$ The importance of low social class in terms of childhood mortality has been highlighted further by another recent study in England and Wales where the authors found that the decline in death rates from injury for children in social classes I and II had been greater than for children in social classes IV and V. ${ }^{36}$ In the USA, Singh and $\mathrm{Yu}^{17}$ noted that the association of socioeconomic status with accidents was stronger than for overall mortality and $\mathrm{Mare}^{25}$ came to similar conclusions. For accidents only, we found that boys had significantly higher rates of death than girls. Studies in the UK and Norway have also shown an excess of childhood accidents in boys, ${ }^{37} 38$ and Singh and Yu have reported a higher overall childhood mortality rate for boys than for girls in the USA. $^{17}$

To develop effective programmes aimed at reducing childhood mortality it is essential to have high quality data systems that allow good epidemiological studies to be conducted. Monitoring of the incidence, prevalence, and trends of childhood deaths, and a clear understanding of their epidemiology, is vital for the development, implementation, and evaluation of appropriate policies and programmes aimed 
at prevention. The importance of good quality data and epidemiological surveillance in terms of childhood accidents has been specifically recognised by a number of authors. ${ }^{139-41}$

In our study, the availability of linked high quality data on the total population has allowed us to extract information that will be useful in planning and monitoring programmes to reduce childhood deaths in Western Australia. The most striking factors contributing to childhood mortality were Indigenous status and socioeconomic characteristics, which agrees with the recent literature, where poverty and its serious consequences on child health have been highlighted. ${ }^{15} 42$

The most important groups in terms of the prevention of childhood mortality were Indigenous children, young mothers, single mothers, and children who were preterm or of low birth weight. In close collaboration with the Indigenous community, attempts must be made to ascertain and implement the most appropriate strategies to prevent deaths in this population. Measures must be taken to curb road traffic accidents and living conditions must be improved to decrease the risk of infections. ${ }^{24}$ Extra information and advice about safety guidelines and current preventive strategies such as the importance of adequate immunisation, adult supervision of children while swimming, child restraints in motor vehicles, and fire detectors should be given to all at risk groups. In the UK, the importance of the role of the health visitor in preventing childhood accidents has long been recognised, ${ }^{43}$ and a similar scheme might be an appropriate way to deliver such information and services to these groups. For the Indigenous population, such programmes would have to be closely linked with community development processes and need to be conducted and staffed from within the communities as far as possible. ${ }^{24}$ There appear to be social class differences in compliance with safety practices and it has been suggested that this reflects class differences in cultural and material resources. ${ }^{2}$ Thus, the groups at higher risk require not only the knowledge of safety laws and guidelines but also the resources to implement them.

Dr Alessandri was funded by a postdoctoral fellowship from the public health research and development grants committee of the National Health and Medical Research Council of Australia. This was the last paper written by Dr Alessandri before her death in August, 1997. We wish to pay tribute to her intellect and enormous courage, determination, and altruism. We thank Mrs V Gee (Western Australian midwives' notification system, Health Department of Western Australia) for her support and access to data. We would also like to thank the Perth and Country Coroners' Offices, the forensic pathology section of the Western Australia State Health Laboratory ogy section of the Western Australia State Health Laboratory birth defects registry of Western Australia for their cooperation birth defects registry of Western Australia for their cooperation and assistance with postmortem records. The Registrar General of Western Australia and the Australian Bureau of Statistics are acknowledged for providing access to birth and
death information. We thank $\operatorname{Dr} S$ Eades of the Perth Aborigideath information. We thank Dr S Eades of the Perth Aborigi-
nal Medical Service for reviewing the manuscript, and Ms N Fitzgerald for clerical assistance.

1 Deane M. Child accident data: accessible and available? $\mathcal{f}$ Public Health Med 1993;15:226-8.

2 Sparks G, Craven MA, Worth C. Understanding differences

between high and low childhood accident rate areas: the between high and low childhood accident rate areas: the
importance of qualitative data. $f$ Public Health Med importance of
3 MacKellar A. Deaths from injury in childhood in Western Australia. 1983-1992. Medical fournal of Australia 1995; 162:238-42.

4 Addor V, Santos-Eggimann B. Population-based incidence of injuries among preschoolers. Eur F Pediatr 1996;155: $130-5$.

5 Jorgensen IM. Fatal unintentional child injuries in Denmark. Dan Med Bull 1996;43:92-6.

6 Rivara FP, Grossman DC. Prevention of traumatic deaths to children in the United States: how far have we come and where do we need to go? Pediatrics 1996;97:791-7.

7 Read A, Stanley F. Postneonatal mortality in Western Australia 1970-1978. Australian Paediatric fournal 1983; 19:18-22.

8 Kliewer EV, Stanley FJ. Stillbirths, neonatal and postneonaal mortality by race, birthweight and gestational age. $\mathcal{f}$ Paediatr Child Health 1993;29:43-50.

9 Alessandri LM, Read AW, Stanley FJ, Burton PR, Dawes VP. Sudden infant death syndrome and infant mortality in Aboriginal and non-Aboriginal infants. $f$ Paediatr Child Health 1994;30:242-7.

10 Stanley FJ, Croft M, Gibbins J, Read AW. A population database for maternal and child health research in Western Australia using record linkage. Paediatr Perinat Epidemiol 1994;8:433-47.

11 World Health Organisation. Manual of the international statistical classification of diseases, injuries and causes of death. Itatistical classification of diseases, injuries and causes of death. World Health Organisation, 1977.

12 Bower C, Rudy E, Ryan A, Forbes R, Grace L. Report of the Birth Defects Registry of Western Australia. King Edward Memorial Hospital, Centre for Women's Health, Subiaco: October 1996.

13 SAS Institute Inc. SAS procedures guide, version 6, 3rd ed. SAS Institute Inc, Cary NC: 1985.

14 Dean AG, Dean JA, Burton AH, Dicker RC. EpiInfo, version 5, a word processing, data base, and statistics program for epidemiology on microcomputers. Stone Mountain, Georgia: USD miology on microcomp.

15 Wadsworth M, Kuh D. Are gains in child health being undermined? Dev Med Child Neurol 1993;35:742-5.

16 Elmen H. Death rates and causes of death among children and youth in Goteborg, Sweden 1971-85. Scand F Soc Med 1994;22:249-55.

17 Singh GK, Yu SM. US Childhood mortality, 1950 through 1993: trends and socioeconomic differentials. Am F Public Health 1996;86:505-12.

18 Moodie PM. Mortality and morbidity in Australian Aboriginal children. Medical fournal of Australia 1969;1: $180-5$.

19 Munoz E, Powers JR, Mathews JD. Hospitalisation patterns in children from 10 Aboriginal communities in the Northern Territory. Medical fournal of Australia 1992;156:52428 .

20 Australian Bureau of Statistics. The health and welfare of Australia's Aboriginal and Torres Strait Islander peoples. Canberra: Australian Government Publishing Service, 1997

21 Young TK. Mortality pattern of isolated Indians in northwestern Ontario: a 10-year review. Public Health Rep 1983;98:467-75.

22 MacWilliam L, Mao Y, Nicholls E, Wigle DT. Fatal accidental childhood injuries in Canada. Can 7 Public Health 1987;78:129-35.

23 Trovato F. Mortality differentials in Canada, 1951-1971: French, British and Indians. Cult Med Psychiatry 1988;12: 459-77.

24 Torzillo P, Kell C. Contempory issues in Aboriginal public health. In: Reid J, Trompf P, eds. The health of Aboriginal
Australia. Sydney, Australia: Harcourt Brace Jovanovich Australia. Sydney, Australia: Harcourt B

25 Mare R. Socioeconomic effects on child mortality in the United States. Am f Public Health 1982;72:539-47.

26 Wise PH, Kotelchuck M, Wilson ML, Mills M. Racial and socio-economic disparities in childhood mortality in Boston. N Engl f Med 1985;313:360-6.

27 Jolly DL, Nolan T, Moller J, Vimpani G. The impact of poverty and disadvantage on child health. 7 Paediatr Child Health 1991;27:203-17.

28 Division of Injury Control, Center for Environmental Health and Injury Control, Centers for Disease Control. Childhood injuries in the United States. Am $\mathcal{F}$ Dis Child 1990;144:627-46.

29 Read AW, Gibbins J, Stanley FJ, Morich P. Hospital admissions before the age of 2 years in Western Australia. Arch Dis Child 1994:70:205-10.

30 Butler NR, Bonham DG. Perinatal mortality. The first report of the British perinatal mortality survey. Edinburgh and London: E \& S Livingstone Ltd, 1963.

31 National Center for Health Statistics. Proceedings of the international collaborative effort on perinatal and infant mortality. Maryland: US Department of Health and Human Services, 1992.

32 Judge K, Benzeval $M$. Health inequalities: new concerns about children of single mothers. BMF 1993;306:677-80.

3 Larson CP, Pless IB, Risk factors for injury in a 3-year-old birth cohort. Am F Dis Child 1988;142:1052-7.

34 Scholer SJ, Hickson GB, Mitchel EF, Ray WA. Persistently increased injury mortality rates in high-risk young children. Arch Pediatr Adolesc Med 1997;151;1216-19.

35 Roberts I, Pless B. Social policy as a cause of childhood accidents: the children of lone mothers. BMF 1995;311: 925-8. 
36 Roberts I, Power C. Does the decline in child injury mortality vary by social class? A comparison of class specific mortality in 1981 and 1991. BMf 1996;313 $784-6$

37 Wadsworth J, Burnell I, Taylor B, Butler N. Family type and accidents in preschool children. I Epidemiol Community Health 1983;37:100-4.

38 Samuelsen SO, Borge AI, Magnus P, Bakketeig LS. Temporal and regional trends in fatal childhood injuries in Norway 1971-1989. Scand F Soc Med 1993;21:17-23.

39 Gaffney BP. Use of coroner's reports for surveillance of accidental death. F Public Health Med 1993;15:272-6.

40 Laraque D, Barlow B, Durkin $M$, Heagarty $M$. Injury prevention in an urban setting: challenges and successes. Bull N Y Acad Med 1995;72:16-30.

41 Murray CLJ, Lopez AD. Mortality by cause for eight regions of the world: global burden of disease study. Lancet 1997;349:1269-76.
42 Montgomery LE, Kiely JL, Pappas G. The effects of poverty, race, and family structure on US children's health: data from

43 Marsh P, Kendrick D, Williams EI. Health visitors' knowledge, attitudes and practices in childhood accident prevention. F Public Health Med 1995;17:193-9.

\section{Editors' note}

The authors have indicated that the Indigenous people of Australia prefer "Indigenous" to be spelt with a capital "I". While this is not usual journal style we have complied with the authors' request.

\section{Archives of Disease in Childhood- http:// www.archdischild.com}

Visitors to the world wide web can access the Archives of Disease in Childhood either through the BMJ Publishing Group's home page (http://www.bmjpg.com) or directly by using its individual URL (http://www.archdischild.com). There they will find the following:

- Current contents list for the journal

- Contents lists of previous issues

- Members of the editorial board

- Subscribers' information

- Instructions for authors

- Details of reprint services

A hotlink gives access to:

- BMJ Publishing Group home page

- British Medical Association web site

- Online books catalogue

- BMJ Publishing Group books

- Royal College of Paediatrics and Child Health home page (www.rcpch.ac.uk)

\section{Full text site}

A full text web site is being developed for the Archives which will be available in early 1999 . Suggestions from visitors about features they would like to see are welcomed. They can be left via the opening page of the BMJ Publishing Group site or, alternatively, via the journal page, through "about this site". 